\title{
Representações sociais da natureza \\ e jornalismo especializado: contribuições para repensar a educação ambiental
}

\author{
Joy de Giacomini Martínez
}

Universidade Federal do Paraná, Curitiba, Brasil.

Email: joydegm@gmail.com

\section{Eloisa Beling Loose}

Universidade Federal do Paraná, Curitiba, Brasil.

Email: eloisa.loose@gmail.com

Resumo: A partir de um diálogo interdisciplinar, as pesquisadoras pretenderam associar as suas pesquisas de mestrado (ambas vinculadas aos conceitos de meio ambiente e natureza) em torno dos diferentes sentidos atrelados à educação ambiental (EA). Debate-se sobre o papel da EA, especialmente a informal, a partir das representações sociais da natureza detectadas por uma das pesquisas. Por meio da categorização dos significados atribuídos à natureza e de uma análise de conteúdo quanti-qualitativa correlacionada às correntes da EA, abre-se espaço para uma discussão entre o que é considerado adequado pela população e o que a teoria aponta como transformador. Reflete-se, ainda, sobre quais seriam as possibilidades de educação informal na construção de uma concepção mais integradora, baseandose nas funções informativa, pedagógica e política do jornalismo ambiental. Acredita-se que o processo de comunicação e a informação ambiental qualificada é ponto de partida para o exercício efetivo da cidadania.

Palavras-chave: Educação ambiental, jornalismo ambiental, representações sociais, natureza.

\section{Social representations of nature and specialized journalism: contributions to rethink environmental education}

\begin{abstract}
This article results from an interdisciplinary dialogue in which the researchers sought to link their master's degree researches (both related to the concepts of environment and nature) to the various meanings assigned to environmental education (EE). It is debated about the role of EE, especially the informal, starting out from the social representations of nature detected by one of the researches. By categorizing the meanings ascribed to nature and a quantitativequalitative content analysis of correlated EE frameworks, a space is opened for discussion between what is considered appropriate by the population and what the theory points as transforming. It is analyzed, as well, about what are the possibilities for informal education in building a more inclusive conception, based on the informational, educational and political roles of environmental journalism. It
\end{abstract}


is believed that the process of communication and qualified environmental information is a starting point for an effective exercise of citizenship.

Keywords: Environmental education, environmental journalism, social representations, nature.

\title{
Representaciones sociales de la naturaleza y periodismo especializado: contribuciones para repensar la educación ambiental
}

\begin{abstract}
Resumen: Partiendo desde un diálogo interdisciplinario, las investigadoras pretendieron asociar sus investigaciones de maestría (ambas vinculadas a los conceptos de medio ambiente y naturaleza) a los diferentes sentidos enlazados con la educación ambiental (EA). Se debate acerca del papel de la EA, especialmente la informal, a partir de las representaciones sociales de la naturaleza detectadas por una de las investigaciones. Mediante una categorización de los significados atribuidos a la naturaleza y de un análisis cuanti-cualitativo correlacionado a las corrientes de la EA, se abre espacio para una discusión sobre lo que es considerado adecuado por la población y lo que la teoría apunta como transformador. Se reflexiona, además, sobre cuáles serían las posibilidades de la educación informal en la construcción de una concepción más integradora, basándose en las funciones informativa, pedagógica y política del periodismo ambiental. Se considera que el proceso de comunicación y la información ambiental calificada es el punto de partida para un efectivo ejercicio de la ciudadanía.
\end{abstract}

Palabras clave: educación ambiental, periodismo ambiental, representaciones sociales, naturaleza.

$* * *$

\section{Introdução}

Com o intuito de refletir sobre as perspectivas da educação ambiental informal ${ }^{1}$ a partir das representações sociais da natureza e do papel do jornalismo ambiental, as autoras deste texto articulam conhecimentos oriundos de suas dissertações de mestrado, em programas de pós-graduação diferentes, com as discussões próprias do campo da educação voltadas para o enfrentamento dos problemas ambientais. Desta forma, este texto é fruto de um diálogo interdisciplinar entre pesquisadoras dos campos de conhecimento da Biologia e da Comunicação Social que, inseridas no contexto do doutorado em Meio Ambiente e Desenvolvimento da Universidade Federal do Paraná, buscam ponderar sobre o papel da educação ambiental informal, a partir das representações sociais da natureza de cidadãos de Criciúma, Santa Catarina, Brasil, detectadas por meio de pesquisa realizada no período de 2008-2010. O artigo relaciona as representações sociais da natureza com algumas correntes da educação ambiental para, em seguida, discutir o papel do jornalismo sobre meio ambiente ${ }^{2}$ na cristalização ou alteração de ideias sobre as questões ambientais. Metodologicamente, a análise realizada é caracterizada como de conteúdo quanti-qualitativa, ou seja, é uma análise que visa obter, por procedimentos sistemáticos e objeti- 
vos de descrição de conteúdo das mensagens, indicadores que permitam a inferência de conhecimentos relativos a outra realidade que não a da mensagem (Bardin, 1977).

A discussão que segue objetiva mostrar como o jornalismo especializado em meio ambiente pode contribuir para a educação e, assim, auxiliar na transformação realidade socioambiental. Para tanto, são apresentadas as funções informativa, pedagógica e política do jornalismo ambiental (Bueno, 2008) e seu papel como construtor da cidadania é ressaltado. As considerações finais se centram na costura feita pelas autoras de suas pesquisas individuais (Martínez, 2010; Loose, 2010) com os desafios presentes na educação ambiental, de forma a contribuir para outras perspectivas neste campo.

\section{As representações sociais da natureza}

A pesquisa "As representações sociais da natureza: um estudo de caso na cidade de Criciúma-SC" (Martínez, 2010) foi realizada no período de 2008 a 2010 e tratou da relação homem-natureza de maneira interdisciplinar. Envolveram-se conhecimentos da Psicologia Ambiental, Sociologia, História, Antropologia, Filosofia da Linguagem e Educação Ambiental, de forma a dialogarem entre si e estabelecerem conexões que possibilitassem novas compreensões sobre o objeto de estudo em questão. A fundamentação teórica na qual se alicerçou a proposta de investigação foi a Teoria das Representações Sociais (TRS), que tem especial interesse na relação entre indivíduo e sociedade. Surgida na Europa em 1961, com a publicação do estudo de Serge Moscovici, esta teoria se contrapôs à natureza individualizante da maior parte das pesquisas em Psicologia Social da América do Norte (Farr, 1995). A realidade percebida por Moscovici foi além da esterilidade ou mera coleta de informação e compreendia domínios físicos, sociais e culturais, abrangendo assim as dimensões cultural e cognitiva, dos meios de comunicação e das mentes das pessoas, subjetiva e objetiva (Guareschi, 1995).

O posicionamento das representações sociais (RS) sobre a relação indivíduo-sociedade foge tanto do determinismo social - homem como produto direto da sociedade - quanto do voluntarismo puro - sujeito como livre agente. Ao situar o homem no processo histórico, busca um posicionamento mais integrador que também abra lugar para as forças criativas da subjetividade, percepções, afetos e memórias. As representaçõ̃es não seriam, portanto, meras expressões cognitivas (Spink, 1993).

Dessa maneira, se faz necessária uma delimitação mais precisa das RS. Uma definição clássica é a de Jodelet, apresentada por Spink (1993: 300), na qual as RS são conceituadas como:

modalidades de conhecimento prático orientadas para a comunicação e para a compreensão do contexto social, material e ideativo em que 
vivemos. São, conseqüentemente, formas de conhecimento que se manifestam como elementos cognitivos — imagens, conceitos, categorias, teorias — mas que não se reduzem jamais aos componentes cognitivos. Sendo socialmente elaboradas e compartilhadas, contribuem para a construção de uma realidade comum, que possibilita a comunicação. Deste modo, as representações são, essencialmente, fenômenos sociais que, mesmo acessados a partir do seu conteúdo cognitivo, têm de ser entendidos a partir do seu contexto de produção. Ou seja, a partir das funções simbólicas e ideológicas a que servem e das formas de comunicação onde circulam.

Acrescenta-se a isso o fato de serem fenômenos relacionados com um modo particular de compreensão e comunicação que cria a realidade e o senso comum. Ao contemplar indivíduos e objetos, predisposição genética, imagens e hábitos aprendidos, recordações preservadas e categorias culturais se juntam para fazê-las como são vistas: elementos de uma cadeia de percepções, opiniões e noções organizadas. As RS tornam o não familiar em familiar, o que as faz dependentes da memória por esta impedir que sofram modificações repentinas e conceder certa independência dos acontecimentos contemporâneos (Moscovici, 2003).

Ainda segundo Moscovici (2003), toda cognição, toda motivação e todo comportamento somente existem e têm repercussões uma vez que signifiquem algo. Significar implica, por definição, que pelo menos duas pessoas compartilham linguagem, valores e memórias comuns. É isto que distingue o social do individual, o cultural do físico e o histórico do estático. Ao dizer que as representações são sociais afirma-se principalmente que elas são simbólicas e possuem tantos elementos perceptuais quanto os assim chamados cognitivos.

Em vista disso, no estudo de Martínez (2010), fundamentado nesta perspectiva teórica, acessaram-se os valores, significados e visões de mundo comuns aos sujeitos, na sua relação tanto individual quanto grupal com a natureza. A compreensão desta relação pode ter contribuído com posições e orientações de políticas públicas potencialmente incrementadoras da realidade socioambiental, além de servirem de subsídios para a criação de estratégias de educação ambiental adequadas à realidade experimentada pela população.

A pesquisa se fundamentou e justificou principalmente pelo fator que gerou crescimento e enriquecimento na cidade: a descoberta de grandes jazidas de carvão em seu território. Em um curto período, Criciúma passou de vilarejo isolado onde se praticava a agricultura de subsistência a polo regional e chamariz de trabalhadores vindos de todos os cantos do país em busca de emprego. Como consequência, a exploração do carvão trouxe à cidade pessoas, capital, visibilidade e diversas indústrias, ao mesmo tempo em que fomentou o êxodo rural e profundos impactos ao meio ambiente e à saúde da população. Lençóis freáticos foram contaminados, nascentes extintas, o solo erodido, as florestas desmatadas, a fuligem pairava no ar e a 
pirita jazia a céu aberto (Pereira, 2005; Philomena, 2005) enquanto o estado de saúde da população era constantemente afetado. Ainda que atualmente a exploração carbonífera esteja em decadência, os impactos socioambientais perduram; situação que originou o questionamento central da pesquisa: Diante de todos os problemas socioambientais que enfrentou e enfrenta cotidianamente, como a população criciumense percebia e significava a natureza?

Para essa investigação, foram selecionadas três áreas de entornos distintos - uma impactada diretamente pelo carvão, outra no entorno de um parque ecológico e a última com grande fluxo de pessoas, no centro da cidade. Em cada uma delas entrevistaram-se quatro sujeitos com participação comunitária significativa, e a todos foram feitas perguntas que resultassem em uma narrativa orientada que expusesse diferentes questões em torno do tema "natureza". Uma vez que a heterogeneidade do grupo era interessante para uma riqueza de resultados, as idades estiveram no intervalo de 42 a 62 anos, contemplando oito mulheres e quatro homens com escolaridade variando do $5^{\circ}$ ano do Ensino Fundamental a pós-graduação. As atividades profissionais dos entrevistados também foram diversificadas.

No presente artigo, destacaram-se particularmente as inquisições "o que é a natureza para você?” e "conte histórias suas com a natureza da época em que era criança e adolescente”. A análise dessas questões, como referido, foi realizada por meio da análise de conteúdo, utilizando-se o tema como unidade de registro e categorias aglutinadoras baseadas nos escritos de Sauvé (2005) e Morales (2007). Nos trabalhos originais, tais categorias corresponderam a concepções particulares de meio ambiente ligadas a 15 principais correntes de educação ambiental encontradas no Brasil e no mundo ${ }^{3}$. Em vista disso, ainda que não se considere "meio ambiente" e "natureza" como sinônimos, considerou-se que o paralelo era próximo o suficiente para poder ser realizado utilizando-se as mesmas categorias e relações com as correntes. Como se verá mais adiante, tal assunção se mostrou verdadeira ao se detectar a coincidência entre o discurso dos entrevistados em outras questões e os resultados desta análise de conteúdo, evidenciando a validade das categorias para ambos os termos. Destaca-se, por fim, que, das 15 categorias totais foram selecionadas e reconfiguradas sete, as quais apresentaram maior pertinência para a nossa análise:

a) Elementos naturais: os conteúdos contemplados nesta categoria diziam respeito a seres vivos (sem contemplar humanos), formações geográficas (rios, serras, etc.) e demais aspectos da natureza percebidos como alheios e/ou desconectados ao homem, ratificando a dicotomia homem x natureza. Em alguns casos, o conteúdo foi abordado também de forma afetivo-simbólica, tendo sido, então, computado em ambas as categorias, uma vez que não são mutuamente excludentes;

b) Benefício/recurso: água, solo, plantas, animais, dentre outros, foram abordados por uma perspectiva na qual serviriam como recur- 
so ou benefício para os humanos, denotando uma visão utilitarista da natureza que, em alguns casos, foi conectada a crenças religiosas;

c) Problema: a natureza teria problemas a serem resolvidos, como poluição, lixo e degradação em geral, além de fenômenos naturais, como enchentes, também terem sido mencionados. Houve em alguns casos conexão com a categoria "consciência ecológica/ desenvolvimento sustentável”, ainda que em essência se trate aqui de uma apropriação de forma insensata e insensível por parte do homem;

d) Sistema/biosfera: percebida como sistema biológico, incluindo palavras-chave como "planeta" e "ecossistema". Traz uma válida perspectiva científica da natureza, na qual uma abordagem sistêmica permitiria a percepção e compreensão das partes e do todo biofísico;

e) Meio de vida/ambiente: o conceito de natureza é comparado ao de entorno, no sentido de "tudo o que nos rodeia". Não fica claro se aí poderiam incluir-se construções humanas ou se é restrito ao não humano; porém, ao analisarem-se os demais discursos, estes apontam para a segunda opção. De toda forma, ao considerar tudo o que está a sua volta, o sujeito não se integra ao entorno, apenas serve como ponto central;

f) Consciência ecológica/desenvolvimento sustentável: a preocupação com as gerações futuras fica patente, além da importância da educação e da mudança de postura serem defendidas;

g) Valor simbólico/afetivo: aqui são atribuídos sentimentos e valores positivos à natureza, a qual é percebida como apaziguadora do espírito, amorosa e perfeita. Por um lado, esse posicionamento fomenta uma conexão mais aprofundada entre homem e natureza. Por outro, pode recair em um olhar romântico do natural e até mesmo remontar ao aspecto de benefício ao homem.

Como abordado, considera-se que essas categorias não são estanques, uma vez que o discurso é complexo e passível de trazer em si ideias diversas e/ou contraditórias. Em maior ou menor grau existe uma conexão entre todas elas, as quais foram criadas meramente para fins sistemáticos e de análise. Os resultados da análise de conteúdo são apresentados na tabela abaixo, conforme as representações sociais que os 12 entrevistados apresentaram no presente (tempo atual) e em suas memórias (quando respondem às questões relacionadas à sua infância e juventude, portanto, ao tempo passado): 
Tabela 1. Resultados da análise de conteúdo conforme o tempo e as representações sociais dos sujeitos entrevistados na pesquisa de Martínez (2010).

\begin{tabular}{|c|c|c|c|}
\hline Categoria & Passado (\%) & Presente (\%) & Total (\%) \\
\hline Elementos naturais & 44 & 4 & 24 \\
\hline Benefício/recurso & 33 & 30 & 31 \\
\hline Problema & 7 & 19 & 13 \\
\hline Sistema/biosfera & 0 & 7 & 4 \\
\hline Meio de vida/ambiente & 0 & 19 & 10 \\
\hline Consciência ecológica/desenvolvimento \\
sustentável
\end{tabular}

Em razão das diferenças encontradas optou-se por separar os dados de acordo com a perspectiva do período de vida dos entrevistados, as quais sugerem uma mudança de relação e compreensão entre os sujeitos e a natureza. Para facilitar a visualização desse aspecto, a proporção de aparição das categorias em função das idades e o total foram:

Gráfico 1. Proporção das categorias da análise de conteúdo em relação ao período de vida dos entrevistados na pesquisa de Martínez (2010).

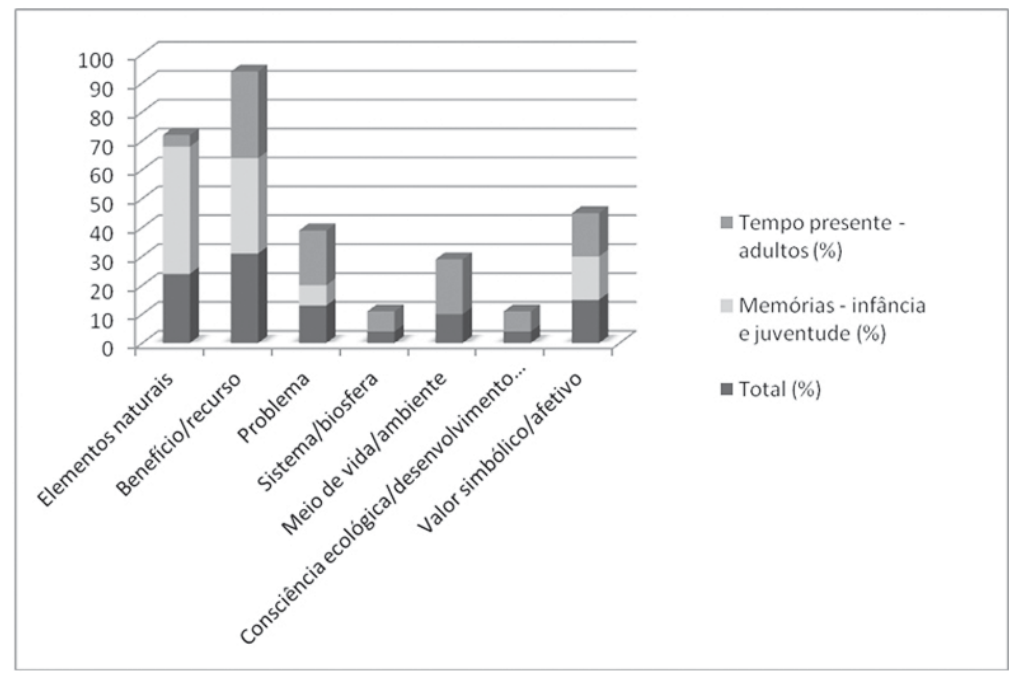


Como se nota, a categoria benefício/recurso apresenta a distribuição mais uniforme. Tal fato era esperado, uma vez que a dissociação entre o homem e a natureza e sua posterior exploração não é apenas relacionada a pontos de vista ou necessidades de civilizações isoladas, mas fruto de correntes de pensamento dominantes, tradições, valores e crenças que reafirmaram ao longo do tempo a "superioridade” do homem, o qual passou a tratar a natureza como bem ou objeto. Abaixo, alguns exemplos de como os entrevistados compreendem a natureza:

E1: "eu acho que a natureza é o ar que eu respiro, né, que nós respira, né. Eu acho que natureza seria praticamente, é... um pulmão pra gente"

E1: “a gente não tinha noção do que é, do que era preservar a natureza, porque nós vivia no meio da natureza, a natureza era uma riqueza, né. A natureza era uma riqueza”

Seja por uma análise positiva ou negativa, nenhum sujeito está livre de trazer consigo tal perspectiva, uma vez que todos somos, de fato, dependentes do que a natureza pode nos proporcionar. Esta é a categoria mais recorrente dentre as representações sociais detectadas nas entrevistas, com 31\% do total.

De forma semelhante, as referências a valor simbólico/afetivo tiveram distribuição equilibrada, evidenciando o mesmo princípio: seja em qual perspectiva for não se pode escapar da construção de sentidos e sentimentos sobre o assunto. Esta categoria condensou 15\% das representações sociais sobre natureza e pode ser percebida nos trechos que seguem:

\section{E2: “a natureza faz parte da minha história"}

\section{E2: “a natureza é a mais profunda expressão de amor e perfeição"}

A segunda categoria mais citada globalmente foi a de elementos naturais (com 24\% das representações sociais totais), que foi mais relacionada ao período passado, à juventude dos entrevistados. Essas memórias foram associadas a situações de aspecto afetivo, criativo, sensorial, experiencial, cognitivo e estético; portanto, diferiria do aspecto meramente cognitivo e pragmático da natureza como recurso. Além disso, o fato de os adultos não terem se detido sobre esse aspecto pode ser indicativo de um distanciamento e não sensibilização frente ao natural. Os exemplos abaixo revelam essa ideia de natureza como algo vinculado estritamente ao meio ambiente sem perceber a relação com o homem:

E3: "se baseia nos elementos: fogo, água, terra e ar que dão existência física a todo ser vivo" colhia flores" 
A percepção de uma natureza problemática (categoria problema) foi preponderante dentre o discurso adulto (tempo atual), embora também existisse nas memórias. Entretanto, a preocupação com equilíbrio ambiental e gerações futuras foi citada apenas no tempo atual e totaliza $13 \%$ dos casos analisados. Isso sugere que as percepções e conhecimentos (como a noção de sistema/biosfera, também citada apenas pela parte adulta) necessários para tanto foram aprendidos ao longo do tempo, embora valores e experiências sejam trazidos desde os seus primeiros anos de vida:

E1: "Nós vivemos em um município que é doente de natureza. Nossa natureza aqui é péssima, né. A gente vê aí tanta degradação, tanta é... a gente vê tanto assim descuido com a natureza, com o meio ambiente”

As outras três categorias tiveram pouca representatividade diante do corpus total da análise. Meio de vida/ambiente reuniu representações que somaram $10 \%$ do total, enquanto sistema/biosfera e consciência ecológica/desenvolvimento sustentável somaram $4 \%$ cada. Isso pode indicar, em especial as duas últimas colocadas, uma falha na educação ambiental recebida pelos sujeitos: além de apresentarem deficiências no entendimento e uso de conceitos científicos, como “ecossistema”, a conexão feita entre homem (enquanto sociedade) e natureza é bastante frágil e escassa. Ao não se considerarem parte do natural e, portanto, da problemática socioambiental, a dicotomia se acentua e não concede espaço a ações que de fato possam envolver os sujeitos e tragam resultados positivos a longo prazo.

Diante disso, nota-se que as principais acepções dos adultos diziam respeito aos benefícios, problemas e entorno; percepções que recaem no utilitarismo, pragmatismo e, em certas situações, pessimismo. De acordo com a cartografia das correntes ${ }^{4}$ da educação ambiental realizada por Sauvé (2005), tais características teriam correlação com as correntes conservacionista/recursista, resolutiva e sistêmica, as quais trazem um enfoque cognitivo dominante.

A corrente conservacionista/recursista, como o próprio nome já aponta, trata da conservação quali-quantitativa dos recursos e da gestão ambiental (da água, do lixo, da energia, etc.), com ênfase no desenvolvimento de habilidades e ecocivismo (Sauvé, 2005). Assim, seus ensinamentos conduziriam ao uso racional da natureza e a um nível ótimo de produtividade dos ecossistemas.

A perspectiva resolutiva, surgida na década de 1970, considera a natureza e meio ambiente como um conjunto de problemas, adotando a visão de educação ambiental proposta pela UNESCO à ocasião da Conferência de Tbilisi. Esta considera dever da educação ambiental

possibilitar ao indivíduo compreender os principais problemas do mundo contemporâneo, proporcionando-lhe conhecimentos técnicos e as qualidades necessárias para desempenhar uma função 
produtiva visando à melhoria da vida e à proteção do meio ambiente, atendo-se aos valores éticos. (...) A educação ambiental deve ser dirigida à comunidade despertando o interesse do indivíduo em participar de um processo ativo no sentido de resolver os problemas dentro de um contexto de realidades específicas, estimulando a iniciativa, o senso de responsabilidade e o esforço para construir um futuro melhor (UNESCO, 1977).

Como se nota, assim como na corrente conservacionista, há o incentivo à ação, de levar a informação à população e desenvolver habilidades para resolver problemas. Já a corrente sistêmica identifica e relaciona os componentes de um sistema ambiental, como os elementos biofísicos e sociais de uma determinada situação ambiental. Assim se chegaria à síntese e totalidade do sistema, levando à possibilidade de tomada de decisões ótimas. Uma vez que toma contribuições da ecologia, biologia e ecologia humanas, há uma convergência aqui com a categoria "sistema/biosfera", a qual considera-se híbrida por várias correntes apropriarem-se do conhecimento científico dito puro.

Em contrapartida, a corrente de educação ambiental afim às representações sociais atreladas à juventude (elementos naturais e, em parte, valor afetivo/simbólico) corresponde à perspectiva naturalista. É centrada na relação com a natureza e pode ter enfoque cognitivo, experiencial, afetivo, espiritual ou artístico, onde se reconhece o seu valor intrínseco e as "lições" que pode trazer. Esta visão é antiga e tem como um de seus defensores Jean-Jacques Rousseau, o qual afirma em seu tratado pedagógico "Emílio" a importância da natureza como dimensão formadora do humano e da vida, apreendida especialmente pelos sentimentos positivos e também experiências penosas:

o desenvolvimento interno de nossas faculdades e de nossos órgãos é a educação da natureza; o uso que nos ensinam a fazer desse desenvolvimento é a educação dos homens; e o ganho de nossa própria experiência sobre os objetos que nos afetam é a educação das coisas (Rousseau, 1995 apud Carvalho, 2006: 102).

Nesse diapasão, Steve Van Matre e Michael Cohen desenvolveram modelos de intervenção que refutam a educação voltada para a simples resolução de problemas e propõem a vivência de experiências cognitivas, afetivas e espirituais. Além de aprender como se dá o funcionamento da natureza, entraria-se em contato com ela por intermédio dos sentidos, resultando em uma conexão homem-natureza com raízes mais profundas que a mera racionalidade (Sauvé, 2005).

Dessa forma, haveria uma distinção entre o que Brügger (1999) chama de adestramento e a educação propriamente dita. O primeiro diria respeito a um processo em que se incentiva a reprodução de conceitos ou desenvolvimento de habilidades técnicas, ignorando-se uma tentativa de integração do conhecimento e de perspectiva crítica e criativa da realidade. 
A educação ambiental defendida aqui é aquela proposta por Reigota (2001), na qual há uma preparação dos cidadãos para que eles exijam e construam outro tipo de relação com a natureza. Para este autor:

A educação ambiental como educação política enfatiza antes a questão "por que" fazer do que "como" fazer. Considerando que a educação ambiental surge e se consolida num momento histórico de grandes mudanças no mundo, ela tende a questionar as opções atuais e o próprio conceito de educação vigente, exigindo-a, por princípio, criativa, inovadora e crítica. (Reigota, 2001: 10).

Barcelos (2012: 21), de forma complementar, avalia que a educação ambiental, tida por ele como uma "exigência da pós-modernidade”, é necessária para a "edificação de um mundo social e ecologicamente mais justo”, revelando a centralidade da educação nas formas e maneiras pelas quais representamos a natureza. Logo, para que haja uma reformulação nas representações sociais dos cidadãos atentando para outro tipo de relação sociedade-natureza, faz-se urgente que a educação ambiental avance em os mais diferentes setores (extrapolando as instituições de ensino formais). Nesse sentido, aponta-se o jornalismo especializado em meio ambiente como um poderoso aliado na disseminação de ideias que possam gerar questionamentos e, quiçá, promover mudanças para a compreensão e ação da crise ambiental contemporânea.

\section{O caráter educativo do Jornalismo Ambiental}

O jornalismo especializado em meio ambiente, que compreende os fundamentos e acepções do campo ambiental, pode contribuir com o alargamento e a difusão da educação ambiental aqui defendida. Mais que noticiar sobre fenômenos e fatos relacionados ao meio ambiente, o jornalismo ambiental tem a função social de informar com qualidade a seus públicos, de modo que eles possam conhecer seus direitos e deveres, os problemas e as discussões a eles relacionados, e agir em prol da sustentabilidade da vida. Este jornalismo está intimamente ligado ao jornalismo cívico, pois ambos preocupam-se com a revitalização da vida pública, com a democracia e com a maior participação e interesse dos cidadãos (Loose, 2010). Destarte, da mesma forma que a educação ambiental apresentada por Reigota (2001), o jornalismo ambiental também apresenta papel político, no sentido de ser promotor de ações e mudanças.

Em pesquisa realizada no período de 2008-2010 sobre as estratégias discursivas e os sentidos apresentados em quatro revistas ambientais brasileiras especializadas em meio ambiente ('Terra da Gente', 'Mãe Terra', 'Sustenta!' e 'Aquecimento Global'), foi constatado que cada publicação constrói um discurso particular sobre as questões ambientais, porém existe a predominância de um olhar humanista, preocupado com as relações entre homem e natureza. As marcas discursivas que tentam trazer o leitor para o texto e fazê-lo refletir sobre suas atitudes nos leva 
a ter uma ideia de meio ambiente complexa e integrada com o cotidiano do homem urbano.

Quanto às estratégias, especificamente, houve maior recorrência daquelas atreladas à aproximação e ao estímulo à mudança de hábitos do leitor, ainda que as visivelmente pedagógicas, relativas ao ensinar, educar, explicar os conceitos, também estivessem constantemente presentes. $\mathrm{O}$ estudo pode comprovar o esforço do trabalho realizado em nichos especializados (caso das revistas ambientais) para mudanças de percepções e a inclusão de novas representações sobre meio ambiente. Por produzir discursos institucionalizadores de ideias, noções e formas de agir, a prática jornalística deve ser incorporadora de outros sentidos, de novas maneiras de ver e se relacionar com o ambiente. Afinal, "se o compromisso do jornalismo é com o interesse público, também o é com as questões ambientais” (Loose, 2010).

Wilson Bueno (2008) realizou uma classificação sobre as funções do jornalismo ambiental, na qual há um destacado espaço para a política, como forma de mobilizar a sociedade. Também trata da função informativa, que deveria preencher a necessidade de o leitor estar em dia com os temas atuais, e da função pedagógica, atrelada à explicação dos motivos e apontamento das soluções para os públicos. O sentido de levar a informação ambiental para um público leigo, não especializado, está intrincado na expectativa de futuras mudanças de hábitos e valores. Para Bueno (2008: 110) essa função

incorpora também uma vigilância permanente com respeito à ação dos governantes que, por omissão ou comprometimento com os interesses empresariais ou com grupos privilegiados da sociedade, não elaboram e põem em prática políticas públicas que contribuem efetivamente para reduzir a degradação ambiental.

Diante disto, o jornalismo ambiental fundamenta-se em uma série de responsabilidades que correspondem aos anseios da educação ambiental. Barcelos (2012) lembra que não é possível desvincular a educação ambiental da história, da cultura, da política, das crenças, mitos e ritos de cada sociedade, sendo o jornalismo de meio ambiente um recurso valioso sob este olhar, já que se encontra disponível no cotidiano das pessoas nos diferentes meios de comunicação e depende da contextualização espaçotemporal-social para se fazer compreendido.

Acrescenta-se que o jornalismo, de forma geral, pode ser visto como um processo de atribuição de representações, visto que as notícias são construídas por meio da linguagem, dentro de certas regras e concepções. Representar é entendido aqui como um movimento de duplicação, de interpretação de algo que está fora e precisa ser apresentado a um público amplo e heterogêneo. Os modos como se organizam as palavras não são mecânicos, eles estão ligados aos sentidos que o enunciador (neste caso o jornalista) precisa e quer transmitir. Fausto Neto (2004) diz que as 
representações são resultados de operações feitas junto às linguagens que, por sua vez, geram a parte visível - os textos. Estas podem ser observadas como matrizes culturais porque são sistematicamente significadas pelos processos de produção de sentidos de todos os campos sociais, apesar de só ganharem mais visibilidade por meio da mídia. Assim, pode-se afirmar que as representações são oriundas dos discursos que circulam na sociedade. O campo jornalístico, devido à legitimidade que lhe é constituinte, imputa uma dimensão maior às representações que são postas em seu domínio ou mesmo criadas por ele.

Contudo, vale sublinhar que desde que nascemos somos interpelados por muitas representações, sejam elas oriundas da família, escola, meios de comunicação, amigos, universidade... A subjetividade do ser humano seleciona algumas delas e, consciente, subconsciente ou inconscientemente, acaba por reproduzi-las para aqueles que os cercam. Com isso, explica-se que as representações não são resultados dos discursos jornalísticos ou dos meios de comunicação. As representações são criadas e multiplicadas por todos. Fazem parte da prática social e da interação humana. O que os discursos jornalísticos são capazes de fazer é aumentar o potencial de reprodutibilidade e associá-las a sua credibilidade, dando, assim, maior visibilidade a elas. Diante de tais afirmações, é manifesto que a força embutida pelos discursos jornalísticos, quando constrói e/ou reproduz, possibilita que a sociedade seja massivamente atingida por representações advindas de um mesmo lugar - o campo jornalístico.

É importante explicar esta relação entre jornalismo e representações sociais, pois ela também engloba a discussão sobre educação ambiental informal. Como foi mostrado na primeira parte do texto, as representações sobre a natureza são bastante variadas e, ainda que as pessoas estejam vivenciando as mesmas questões ambientais, a forma de se relacionar com a natureza não é a mesma.

O processo educativo por meio da reflexão sobre as representações da natureza e/ou a partir das representações que são disseminadas pelo jornalismo permite que haja questionamentos e abre oportunidades para que surjam outras formas de perceber o lugar onde vivemos.

A partir da construção e/ou desconstrução de representações, às vezes já cristalizadas no imaginário dos educandos e educandas, podemos construir outras representações trazendo para o diálogo, para a conversa ou radicalizando alguns valores, conceitos como solidariedade, justiça, paz, cuidado, democracia, fraternidade, amor, liberdade e reconhecimento do outro (Barcelos, 2012: 90).

Os valores apontados acima podem e devem fazer parte da prática jornalística, visto que um dos papéis desta atividade é tornar visíveis as preocupações que emergem da sociedade. Para cumprir seu compromisso social de informar e empoderar os indivíduos para o exercício pleno da cidadania, o jornalismo precisa ir além da exposição dos acontecimentos, 
explicando-os e relacionando-os com o cotidiano de cada público. Girardi \& Loose (2009: 2-3) pontuam algumas interfaces entre o jornalismo ambiental e a educação:

A difusão de uma postura ética para o restabelecimento do equilíbrio da vida já coloca o jornalista ambiental como agente da propagação da proteção de onde vivemos, oferecendo visibilidade e argumentos para cobranças do poder público. Para isso, a adequação pertinente ao público-alvo é fundamental para que haja entendimento real da informação. Além de colaborar para o acréscimo de conhecimentos e a estruturação de uma postura mais ética diante do meio ambiente, os veículos de comunicação podem iniciar o público de amanhã a interessar-se por meio ambiente.

Conclui-se, assim, que o trabalho jornalístico executado com responsabilidade e qualidade promove novas atitudes e amplia a discussão sociopolítica, contribuindo e exercendo a educação ambiental informal, além de promover a cidadania. A partir da construção e disseminação de informações ambientais que aproximem os públicos de suas realidades locais e que permitam a reflexão sobre suas formas de se relacionar com a natureza/ meio ambiente, o jornalismo passa a atuar também como parte da educação ambiental informal, ou seja, aquela realizada fora do âmbito escolar e que busca sensibilizar as pessoas de forma espontânea.

Por ter um papel relevante na sensibilização da população quanto às problemáticas ambientais, o jornalismo especializado mostra-se como um dos vetores da educação ambiental informal, pois objetiva gerar um melhor entendimento das complexas relações existentes entre homem e natureza. Mais que denunciar degradações ou desejar conscientizar os públicos sobre suas responsabilidades, o jornalismo ambiental busca ampliar a visão de mundo de seus públicos, colaborando com o empoderamento dos indivíduos para que eles exerçam da melhor forma possível seus direitos como cidadãos.

Nesse sentido, é preciso perceber que este jornalismo comprometido com as questões ambientais tem muito a contribuir com o dilatamento de representações sociais reduzidas sobre a natureza e também com a produção de outras ideias, mais coincidentes com a aproximação do homem com a natureza e com a emergência de se ter práticas sociais mais sustentáveis. O reforço ou o apagamento de certas visões de mundo que são difundidas pela mídia em geral (e pelo jornalismo em específico) contribuem para a formação (e por que não educação?) da opinião pública. Morais (2004, p.87) afirma que o espaço da educação é, necessariamente, o da comunicação, pois implica, em um campo social, o "trânsito de ideias e sentimentos, valores e sugestões comportamentais”. Assim, pensar o jornalismo ambiental, como mais uma maneira de educar espontaneamente a população para o enfrentamento das questões ambientais que estão postas reúne as três funções discutidas por Bueno (2008): a informativa, a pedagógica e a política. 


\section{Considerações finais}

Tendo em vista os resultados encontrados a partir da categorização das representações sociais obtidas nas entrevistas sobre a ideia de natureza, constata-se que no contexto de Criciúma (uma cidade com evidentes problemas socioambientais) os moradores possuem certo distanciamento e uma compreensão parcial e fragmentada das imbricações presentes na relação sociedade-natureza. Pensando a partir de algumas categorias da educação ambiental, as correntes mais críticas e que trazem as representações de uma natureza mais complexa não têm peso nas entrevistas analisadas. Isso pode ter ocorrido por inúmeros fatores (como a ausência da educação ambiental ou de valores ambientais positivos no âmbito familiar, pela formação antropocêntrica, pela dificuldade de acesso a informações mais qualificadas, etc.), mas faz com que surja a questão: como alterar tais perspectivas? Como tornar essas pessoas agentes de transformação ambiental?

A educação ambiental informal, apresentada aqui através do jornalismo especializado em meio ambiente, tem o potencial de trazer e explicar outras representações sociais, mais comprometidas com a discussão da relação homem-natureza. Soma-se a isso o fato de que a compreensão das representações sociais existentes é fundamental para avaliar o que precisa ser reforçado e quais aspectos necessitam de transformação para se tornarem mais ambientalmente positivos e responsáveis. Por utilizar artifícios (estratégias discursivas) que atraiam e facilitem a compreensão do público, e carregar consigo a responsabilidade de servir ao interesse público, o jornalismo ambiental tem muito a contribuir para a expansão daquelas correntes da educação ambiental que propõem mudanças mais profundas e relações mais integradoras, já que a dimensão política da atividade está em contato com aspectos de cunho informativo e pedagógico.

Considera-se que nenhuma corrente da educação ambiental seja capaz de abarcar e transformar por si só todas as dimensões e problemas encontrados na realidade, uma vez que podem trazer incompletudes e imperfeições de acordo com o contexto em que se inserem. Existem, porém, alguns fundamentos ou princípios indispensáveis e transversais à maioria das correntes, como o da sustentabilidade (que mediante a lógica crítica, autônoma e dialógica busca contribuir para a promoção de sociedades sustentáveis), o da interdisciplinaridade (que proporciona a (re)construção de novos saberes, valores e conhecimentos para a constituição e incorporação de outra racionalidade) e o da complexidade (que preconiza a dimensão da totalidade e da perspectiva sistêmica a fim de auxiliar na compreensão e incorporação do saber ambiental). Tais pontos são apresentados por Morales (2007) - e endossados por estas autoras - como formas de romper com as visões reducionistas sobre meio ambiente que ainda estão presentes na sociedade.

Assim, a própria leitura crítica e reflexiva das notícias ambientais torna-se uma poderosa ferramenta educativa para os sujeitos, especialmen- 
te aquelas provindas de veículos especializados. Entretanto, para que isso ocorra, é necessário que antes haja uma base prévia e sólida de valores e atitudes ambientais positivos, que permita uma interpretação clara e contribuinte para as questões socioambientais enfrentadas nos mais diferentes contextos. Esta base, calcada em representações complexas das interrelações entre sociedade e natureza, deveria iniciar desde os primeiros anos de vida, sendo fortalecida e retroalimentada pelo jornalismo ambiental ao longo da vida do sujeito, proporcionando uma educação continuada, crítica e (auto)reflexiva. Acredita-se que somente dessa forma a educação ambiental com sentido transformador, ligada à cidadania e à emancipação do sujeito, seria, de fato, permanente e geradora de visões de mundo diferentes das que aqui foram verificadas. 


\section{Notas}

${ }^{1}$ Esclarece-se que a educação ambiental, de forma geral, é apresentada na literatura da área com três possibilidades de atuação: a educação formal (que contempla as questões ambientais de forma interdisciplinar a partir dos currículos escolares de cada país), a educação não formal (aquela direcionada à comunidade ou a grupos que não frequentam mais a escola, com o objetivo de melhorar a qualidade de vida das pessoas e fortalecer sua cidadania) e a educação informal (que representa os processos destinados a ampliar a conscientização pública sobre as questões ambientais através dos meios de comunicação, sistemas de informatização, bancos de dados ambientais, etc.). Neste trabalho, a ênfase é dada na educação ambiental informal, compreendida como aquela que extrapola os ambientes institucionalizados dedicados ao ensino e que é realizada de forma espontânea pelo contato com grupos, meios de comunicação, livros e outras ferramentas que auxiliam na sensibilização de outro olhar sobre o meio ambiente.

${ }^{2}$ Neste texto não fazemos distinção entre o conceito de jornalismo ambiental e o de jornalismo de meio ambiente. Independente do termo utilizado, adotamos a perspectiva do Grupo de Pesquisa Jornalismo Ambiental (CNPq/UFRGS), instituído em 2008 e que "tem por objetivo realizar estudos que venham a contribuir com a constituição de um referencial teórico para o jornalismo ambiental. O caminho que pretende seguir aglutina os estudos das teorias do jornalismo, especialmente no campo da ética e da função social do jornalismo na construção da cidadania, com os paradigmas complexo e da ecologia profunda e a corrente teórica ecossocial sobre sustentabilidade. Em síntese, busca incorporar um olhar ecológico ao jornalismo, que contemple a sustentabilidade da vida no Planeta, a solidariedade, a justiça social e a construção da paz” (Girardi et al, 2012, p.133).

${ }^{3}$ É pertinente apontar que essa generalização é feita por considerar-se a dimensão internacional característica da educação ambiental, a qual apresenta fundamentos em um cenário amplamente mundializado e de forte fluxo intercambiante de ideias entre países. Ultrapassando-se essas fronteiras, ao mesmo tempo em que esse diálogo em rede constitui o campo, incide sobre experiências nacionais, regionais e locais (Sato \& Carvalho, 2005).

4 “A noção de corrente refere-se aqui a uma maneira geral de conceber e de praticar a educação ambiental. Podem se incorporar, a uma mesma corrente, uma pluralidade e uma diversidade de proposições. Por outro lado, uma mesma proposição pode corresponder a duas ou três correntes diferentes, segundo o ângulo sob o qual é analisada. (...) as correntes não são, no entanto, mutuamente excludentes em todos os planos: certas correntes compartilham características comuns” (Sauvé, 2005: 17). 


\section{Bibliografía}

Barcelos, Valdo (2012), Educação Ambiental - sobre princípios, metodologias e atitudes, Vozes, Petrópolis.

Bardin, Laurence (1977), Análise de Conteúdo, Edições 70, Lisboa.

Bueno, Wilson da Costa (2008), “Jornalismo ambiental: explorando além do conceito”, en Girardi, Ilza; Schwaab, Reges (org.), Jornalismo ambiental - Desafios e reflexões, Editora Dom Quixote, Porto Alegre.

Brügger, Paula (1999), Educação ou adestramento ambiental?, Letras Contemporâneas, Florianópolis.

Carvalho, Isabel (2008), Educação ambiental: a formação do sujeito ecológico, Cortez, São Paulo.

Farr, Robert M. (1995), “Representações sociais: a teoria e sua história”, en Guareschi, Pedrinho;

Jovchelovich, Sandra (orgs.), Textos em representações sociais, Petrópolis, Vozes, p. 31-59.

Fausto Neto, Antônio (2004), “O jornalismo e os limites da representação”, en Ecos Revista, v. 8, $\mathrm{n}^{\circ}$ 2, jul/dic, Pelotas.

Girardi, Ilza; Schwaab, Reges; Massierer, Carine; Loose, Eloisa Beling. (2012), “Caminhos e descaminhos do Jornalismo Ambiental”, en Comunicação \& Sociedade, v. 34, nº 1, São Bernado do Campo. p. 131-152.

Guareschi, Pedrinho (1995), “'Sem dinheiro não há salvação’: ancorando o bem e o mal entre os neopentecostais”, en Guareschi, Pedrinho; Jovchelovich, Sandra (orgs.), Textos em representações sociais, Petrópolis, Vozes, p. 191-228.

Loose, Eloisa Beling; Girardi, Ilza Maria Tourinho (2009), O Jornalismo Ambiental e seu Caráter Educativo, en Anais do XXXII Congresso Brasileiro de Ciências da Comunicação (Intercom), Curitiba.

Loose, Eloisa Beling (2010), Jornalismo Ambiental em Revista: das Estratégias aos Sentidos, dissertação em Comunicação e Informação, Universidade Federal do Rio Grande do Sul.

Martínez, Joyde Giacomini (2010), As representações sociais da natureza: um estudo de caso na cidade de Criciúma-SC, dissertação em Ciências Ambientais, Universidade do Extremo Sul Catarinense.

Morales, Angélica Góis Müller (2007), A formação do profissional educador ambiental: reflexões, possibilidades e constatações no curso de 
especialização da UFPR, tese em Meio Ambiente e Desenvolvimento, Universidade Federal do Paraná.

Morais, Regis de (2004), Educação, mídia e meio-ambiente, Editora Alínea, Campinas.

Moscovici, Serge (2003), Representações sociais: investigações em psicologia social, Editora Vozes, Petrópolis.

Pereira, Tarciso (2005), As áreas de preservação ambiental do município de Criciúma: um estudo sobre sua importância e utilização como referência à educação ambiental, dissertação em Ciências Ambientais, Universidade do Extremo Sul Catarinense.

Philomena, Gerson Luis de Boher (2005), Cultura do carvão em CriciúmaSC: a história que não se conta, dissertação em Ciências Ambientais, Universidade do Extremo Sul Catarinense.

Reigota, Marcos (2001), O que é Educação Ambiental, Brasiliense, São Paulo.

Sato, Michèle; Carvalho, Isabel (2005), “Itinerários da Educação Ambiental: um convite a percorrê-los”, en Sato, Michèle; Carvalho, Isabel (org.), Educação ambiental: pesquisa e desafios, Artmed, Porto Alegre.

Sauvé, Lucie (2005), “Uma cartografia das correntes em educação ambiental, en Sato, Michèle; Carvalho, Isabel (org.), en Educação ambiental: pesquisa e desafios, Artmed, Porto Alegre.

Spink, Mary Jane P. (1993), “O conceito de representação social na abordagem psicossocial”, Cad. Saúde Públ., Rio de Janeiro, vol. 9, nº 3, p. 300-308, jul/set.

UNESCO (1977), Declaração de Tbilisi, Geórgia. Disponível em: < http:/ /www. mma.gov.br/ port/sdi/ea/deds/pdfs/decltbilisi.pdf >. 